\title{
NBE versus $\mathrm{MCl}$-the slug fest
}

\author{
Om Prakash Yadava ${ }^{1}$
}

Received: 13 February 2018 / Accepted: 19 February 2018 / Published online: 13 March 2018

(C) Indian Association of Cardiovascular-Thoracic Surgeons 2018

There has lately been a lot of brouhaha and a tug of war between the Medical Council of India (MCI) and the National Board of Examinations (NBE) on the issue of equivalence of the degrees issued by each one of them. The MS, $\mathrm{MD}$, DM, and MCh courses are conducted by MCI in University Teaching Hospitals, while the National Board runs the parallel system of education, awards the DNB degree, and is held in non-teaching hospitals, including private sector hospitals. The general impression seems to have been given by MCI that the training in teaching hospitals is far superior to the ones provided under the NBE umbrella. Though we do not have any hard core evidence one way or the other in Indian literature, recently, an article in JAMA Surgery by Sellers et al. [1] has examined a similar debate in the American system where teaching and training in University hospitals was compared to the one offered by non-teaching community hospitals. The authors looked at a huge volume of data covering over 3600 surgeons, 1.2 million plus patients, and covering over 214 training programs in the states of New York, Florida and Pennsylvania in the USA and examined and analyzed the clinical outcomes data for nearly 3,12,000 patients undergoing treatment under 2300 surgeons. Contrary to the general belief, they found that the surgeons training in non-teaching hospitals out-performed those from the teaching hospitals in terms of morbidity, mortality, complications, and survival rates. They also found that these surgeons were more satisfied with the operative experience that they were exposed to in the nonteaching hospitals than their counterparts in the teaching hospitals. Further, it was found that most of the trainees passing out from the non-teaching hospitals settled in to private practice, and the probable reason offered by Dr. Balinger and Kao in an accompanying editorial [2] was "It may give them more opportunities to focus on bread and butter general surgeries instead of the more esoteric cases referred to academic

Om Prakash Yadava

op_yadava@yahoo.com

1 National Heart Institute, New Delhi, India medical centres." Probably smaller number of trainees in these community hospitals also gives them better exposure to clinical work with less time spent on core research and in the animal or experimental labs.

If one were to extrapolate these findings, I think the situation in India is quite analogous. Our private sector hospitals today are no less than the community hospitals in the western world, and they do give an exposure to a wide variety of cases rather than just referral cases to be found in some of the more celebrated and hallowed organizations like AIIMS and PGIs. The only difference that one may find is that in our scenario, most consultants are honorary, and they work on the "Pay for Service" model and therefore may not devote dedicated time in teaching and training students, as these are nonreimbursable activities.

Speaking for ourselves, it is no open secret that a lot of busy cardiothoracic surgeons use their trainees only to do pre- and post-operative workup of cases, and intra-operatively, they are used for only sundry and collateral jobs like opening and closing the chest and conduit harvesting in coronary surgery. Therefore, it should be made mandatory by the regulatory bodies that all consultants working in a particular department which is recognized for post-graduate teaching and training must have dedicated, non-operating sessions, where only training and teaching activities can go on, and for these sessions, those who are not on full-time model must be adequately reimbursed to ensure that they do their job with due diligence and sincerity. As they say, there is no free lunch, and if you do not reimburse these busy consultants for the teaching episodes, we cannot expect them to show sincerity of purpose towards transfer and dissemination of knowledge.

One thing however looks reassuring and heartening that if intended well, training at both, the teaching as well as nonteaching hospitals, is equivalent or at least can be made equivalent. Therefore, the parallel system of medical higher education, retained by the much maligned National Medical Commission, has much evidence base going for it for a big thumbs up. Let us, the Doctors, not resist for the sake of resisting and even government must show magnanimity by 
not imposing disruptive changes in practice of medicine till validated by meaningful studies and robust evidence base to support their use.

Similar studies are needed to address other burning questions like-will BSc Community Medicine produce halfbaked doctors; will bridge course for Dental Doctors compromise quality of care; will AYUSH doctors writing allopathic medicines be deleterious to community health? A pilot study looking at these issues may well be the order of the day, before widespread adoption.

\section{References}

1. Sellers MM, Keele LJ, Sharoky CE, Wirtalla C, Bailey EA, Kelz RR. Association of surgical practice patterns and clinical outcomes with surgeon training in university or nonuniversity-based residency programme. JAMA Surg. 2018; https://doi.org/10.1001/jamasurg.2017. 5449.

2. Balinger KJ, Kao LS. Non university-based surgeons coming up anything but short in solutions to the future surgeon shortage. JAMA Surg. 2018; https://doi.org/10.1001/jamasurg.2017.5471. 